\title{
Voltammetric Determination of Sudan 1 in Food Samples Using Its $\mathrm{Cu}(\mathrm{II})$ Compound
}

\author{
Kuddusi Karaboduk ${ }^{1 *}$ \\ and Erdoğan Hasdemır²
}

'Life Sciences Application and Research Center, Gazi University, TR-06830 Golbasi, Ankara, Turkey 2Faculty of Sciences, Department of Chemistry, Gazi University, TR-06500 Besevler, Ankara, Turkey

Received: 23 January 2018 Accepted: 15 November 2018

\section{(c) (i) ()}

*Corresponding author:

Phone: +903124854493;

Fax: +903124846271;

E-mail: kuddusi82@gmail.com,

kuddusi@gazi.edu.tr

\section{SUMMARY}

In this work, we developed a sensitive, simple and convenient electrochemical method to determine Sudan 1 in food samples using its $\mathrm{Cu}$ (II) coordination compound. Using phosphate buffer solution at $\mathrm{pH}=5.0$ as supporting electrolyte $(75 \%$ methanol), differential pulse voltammetry and 6 -fold concentration of $\mathrm{Cu}(\mathrm{III})$, the electrochemical oxidation signal of Sudan 1-Cu(II) coordination compound at glassy carbon electrode significantly increased when compared to the one without the added $\mathrm{Cu}(\mathrm{II})$. The experimental conditions such as the amount of methanol, $\mathrm{pH}$, the concentration of $\mathrm{Cu}(\mathrm{II})$ and the instrumental parameter were optimized for the determination of Sudan 1. Under the optimal experimental conditions, the oxidation peak current of Sudan 1 was proportional to its concentration in two ranges: $0.04-0.09$ to $0.09-5.3 \mu \mathrm{M}$ with a detection limit of $0.71 \mathrm{nM}(S / N=3)$. The interference effects of Sudan 2-4 with the determination of Sudan 1 was also evaluated. The developed method was successfully applied to tomato, chilli sauces, ketchup and chilli powder. The analysis results of Sudan 1 in food samples obtained by the proposed method were in a good agreement with the reference values detected by HPLC.

Key words: Sudan 1, voltammetric determination, $\mathrm{Cu}(\mathrm{II})$, food analysis

\section{INTRODUCTION}

For food industries, colour is the first indicator of the quality of the food. Organic colourants are often used to enhance both the sales and visual aesthetics of foods. Food colourants are usually classified into pigments from natural sources and artificially synthesized dyes $(1,2)$. Azocompounds, a kind of synthetic organic colourants, are among the widely used food colourants. The azo dye molecules with the help of biocatalyst are transformed into respective aromatic amines, which are more toxic to the environment than the intact dye molecule (3). Sudan dyes, mainly Sudan 1, Sudan 2, Sudan 3 and Sudan 4, are non-ionic fat-soluble dyes. These phenyl-azoic derivatives are classified by the International Agency for Research on Cancer (IARC), Lyon, France, as category 3 carcinogens. They can induce some forms of liver and bladder cancer in animals (4) so their use in food is banned in most countries, including the European Union (5). However, Sudan 1 (1-phenylazo-2-napthol), which is a carcinogenic compound containing an azo group, is still used in foodstuffs as additive due to its low price, bright and stabile colour (6-8). Therefore, developing a sensitive, suitable and rapid method for the determination of Sudan 1 is very important and essential.

Until now, several analytical methods have been developed for the analysis of Sudan 1, such as capillary liquid chromatograpy (9), Raman spectroscopy (10), UFLC-MS/MS (11), HPLC (12-14) and fluorescence spectroscopy (15), among which HPLC is preferred for determination of Sudan 1 (16). These techniques are sensitive but they require expensive instruments, time for pretreatment, experienced operators and large amount of organic solvents (17). Apart from that, these instruments are not suitable for fieldwork because they are cumbersome. On the other hand, electroanalytical techniques are cost-effective, simple and use portable instruments, which are easy to handle, and they require short analysis time $(18,19)$. For the electrochemical determination of Sudan 1 , some methods 
using multi-wall carbon nanotube (MWNT) thin film-modified glassy carbon electrode (20), self-assembly ionic liquid-functionalized reduced graphene oxide-gold nanoparticle composites (6), or multi-wall carbon nanotube modified glassy carbon electrode (21) have been reported.

Sudan dyes and their $\mathrm{Cu}$ (II) complexes were investigated both experimentally and theoretically and characterized by analytical and spectroscopic X-ray diffraction methods $(22,23)$.

In this paper, we developed a simple, stable and sensitive electrochemical method for the determination of Sudan 1 in food samples. For the voltammetric determination of Sudan 1, Sudan 1-Cu(II) coordination compound and non-modified glassy carbon electrode were used. Besides, interference effects of Sudan 2-4 were also evaluated for the electrochemical determination of Sudan 1. It was discovered that the proposed method has advantages such as high sensitivity, low detection limit and low cost. The suggested new method was used for the determination of Sudan 1 in tomato, chilli sauces, ketchup and chilli powder.

\section{MATERIALS AND METHODS}

\section{Chemicals}

Phosphate-buffered saline (PBS) tablets were purchased from Oxoid Ltd. (Thermo Fisher Scientific, Basingstoke, UK) and $\mathrm{Cu}^{2+}, \mathrm{Ca}^{2+}, \mathrm{Mg}^{2+}, \mathrm{Al}^{3+}, \mathrm{Na}^{+}, \mathrm{Fe}^{3+}$ and $\mathrm{Zn}^{2+}$ solutions (inductively coupled plasma (ICP) standard, in $2 \% \mathrm{HNO}_{3}$ ) were purchased from Merck (Darmstadt, Germany). Sudan 1 ( $\geq 95 \%)$, Sudan 2 (90\%), Sudan 3 (technical grade), Sudan 4 ( $\geq 80 \%)$, glucose (ACS reagent (analytical reagents of the American Chemical Society)), fructose ( $\geq 99 \%)$, sucrose ( $\geq 99.5 \%)$ and methanol were all purchased from Sigma-Aldrich (Merck, St. Louis, MO, USA). All of them were used without further purification. The tomato, chilli sauces, ketchup and chilli powder were purchased from a local market (Çankaya, Ankara, Turkey). The supporting electrolyte, phosphate buffer $(\mathrm{pH}=5.0)$, was prepared using PBS tablets in methanol (75\%) and $\mathrm{pH}$ was adjusted using $0.1 \mathrm{M} \mathrm{H}_{3} \mathrm{PO}_{4}$ (Sigma-Adrich, Merck) and 0.1 $\mathrm{M} \mathrm{NaOH}$ (Sigma-Aldrich, Merck). All chemicals were of analytical grade. Double distilled water $(18.2 \mathrm{M} \Omega \mathrm{cm})$ was used to prepare the solution.

\section{Apparatus}

Cyclic voltammetry (CV) and differential pulse voltammetry (DPV) measurements were carried out with a PalmSens3 potentiostat/galvanostat (PalmSens BV, Houten, The Netherlands) and CHI 660B (CH Instruments, Inc., Austin, TX, USA). A conventional three-electrode system, consisting of glassy carbon working electrode (MF-2012, 3.0 mm diameter; BASi, West Lafayette, IN, USA), Ag/AgCl reference electrode (MF-2052; BASi) and platinum wire auxiliary electrode (MW-1032; BASi), was used. Moreover, Agilent 1200 series HPLC system (Agilent Technologies, Inc., Santa Clara, CA, USA) was used for Sudan 1 chromatographic analysis on the ACE C18 (250 $\mathrm{mm} \times 4.6 \mathrm{~mm}$ ) column (Advanced Chromatography Technologies Ltd, Aberdeen, UK), with a mobile phase consisting of methanol/acetonitrile ( $40: 60$, by volume) and a constant flow rate of $0.5 \mathrm{~mL} / \mathrm{min}$. The injection volume was $10 \mu \mathrm{L}$ and the column temperature was set at $25^{\circ} \mathrm{C}$. Finally, the wavelength was set at $254 \mathrm{~nm}$ for quantitative analysis.

\section{Analytical procedure}

Phosphate buffer solution ( $\mathrm{pH}=5.0$ ) as supporting electrolyte (75\% methanol) was used for the determination of Sudan 1. Differential pulse voltammograms were recorded from 0.4 to $1.2 \mathrm{~V}$ with the parameters of pulse amplitude of $0.05 \mathrm{~V}$, pulse time of $4 \mathrm{~s}$ and pulse width of $0.025 \mathrm{~s}$. The oxidation peak current values at $0.96 \mathrm{~V}$ were used for the determination of Sudan 1 in the presence of $\mathrm{Cu}(\mathrm{II})$.

\section{Sample preparation}

A mass of $1.0 \mathrm{~g}$ of tomato and chilli sauces, ketchup and chilli powder was weighed exactly and then $40 \mathrm{~mL}$ methanol were added. After $30 \mathrm{~min}$, ultrasonication, the mixtures were filtered through $0.22-\mu \mathrm{m}$ syringe filter (Sartorius, Goettingen, Germany) in a 50-mL volumetric flask and then diluted to 50 $\mathrm{mL}$ with methanol.

\section{RESULTS AND DISCUSSION}

\section{Voltammetric behaviour of Sudan 1 and Sudan 1-Cu(II)}

The electrochemical behaviour of $1.96 \mu \mathrm{M}$ Sudan 1 and Sudan 1-Cu(II) coordination compound was investigated on glassy carbon electrode using cyclic voltammetry (CV) in PBS at $\mathrm{pH}=5.0$ (75 \% methanol). Fig. 1 a shows the cyclic voltammogram of supporting electrolyte (curve A), and the cyclic voltammogram of $1.96 \mu \mathrm{M}$ Sudan 1 in which an oxidation peak was observed at $0.86 \mathrm{~V}$ during the anodic scanning from 0.4 to 1.2 $\mathrm{V}$ (curve B). There is no peak on the reverse scan. Curve $\mathrm{C}$ shows the influence of $\mathrm{Cu}(\mathrm{II})$ on electrochemical oxidation of Sudan 1.

The oxidation peak potential of Sudan 1 shifted from 0.86 to $0.96 \mathrm{~V}$ in the presence of $11.76 \mu \mathrm{M} \mathrm{Cu}(\mathrm{II})$ and the oxidation peak current increased greatly; on the reverse scan, a slightly visible reduction peak appeared at $0.87 \mathrm{~V}$. In addition, the oxidation peak current of Sudan 1-Cu(II) increased remarkably; however, the reduction peak current remained almost unchanged. This may be attributed to the special structure of Sudan 1-Cu(II) complex because it exhibits oxidation waves at more positive potentials as a result of the destabilizing effect of the electron-withdrawing group on the aryl-azo moiety (24). Therefore, with the addition of $\mathrm{Cu}(\mathrm{II})$, Sudan 1 oxidation peak current increased and the sensitivity was enhanced. Besides, the oxidation of Sudan 1 is an irreversible reaction in the presence of $\mathrm{Cu}(\mathrm{II})$, too. Finally, the electrochemical behaviour of $\mathrm{Cu}$ (II) solution $(1.96 \mu \mathrm{M})$ was evaluated in the same medium, but any oxidation or reduction peak was not observed (Fig. 1b, curve B). 
a)

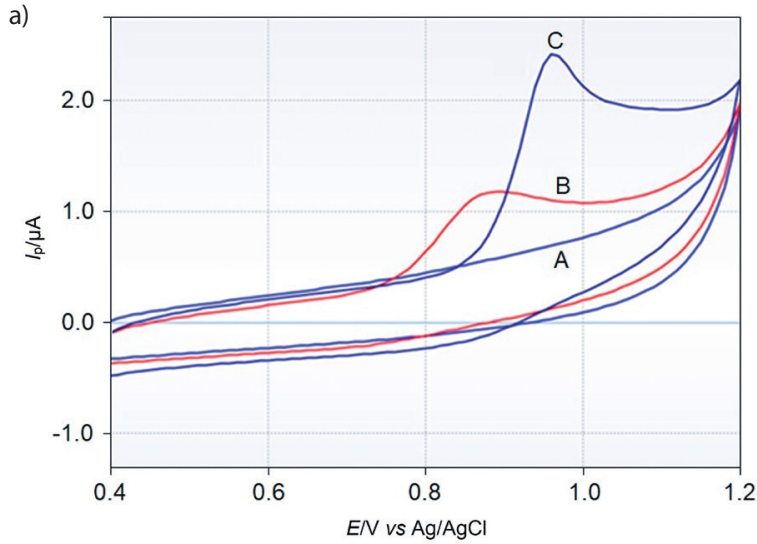

b)

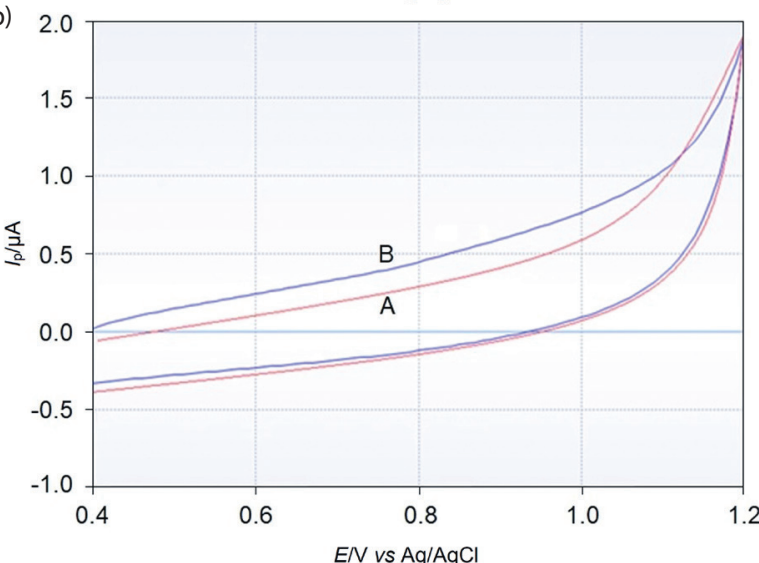

Fig. 1. Cyclic voltammograms recorded on glassy carbon electrode with scan rate $125 \mathrm{mV} / \mathrm{s}$ of: a) supporting electrolyte (phosphate-buffered saline (PBS) at $\mathrm{pH}=5.0$ in $75 \%$ methanol) (curve A), Sudan $1(c=1.96 \mu \mathrm{M})$ in PBS (curve B), and Sudan 1-Cu(II) complex (curve C), and b) PBS (curve A), and solution of $\mathrm{Cu}(\mathrm{II})(c=11.76 \mu \mathrm{M})$ in PBS (curve B)

\section{Effect of $\mathrm{pH}$}

The $\mathrm{pH}$ is always involved in the electrochemical reaction of organic compounds and it exerts significant effect on the reaction speed (18). The influence of $\mathrm{pH}$ on the electrochemical oxidation signal of Sudan 1 was studied at different $\mathrm{pH}$ values (from 2.0 to 12.0) with different supporting electrolytes (75\% methanol) with CV technique and $117.6 \mu \mathrm{M} \mathrm{Cu(II).} \mathrm{Fig.}$ $2 \mathrm{a}$ shows the effect of $\mathrm{pH}$ value on the oxidation peak current of $19.6 \mu \mathrm{M}$ Sudan 1. Sudan 1 oxidation peak potential shifted negatively with the increase of $\mathrm{pH}$ and changed linearly depending on the change in the $\mathrm{pH}$ ranging from 2.0 to 12.0 , which was determined using the following equation:

$$
E_{\mathrm{pa}}=-0.0455 \mathrm{pH}+1.0934\left(\mathrm{R}^{2}=0.924\right)
$$

indicating that the oxidation of Sudan 1 includes the protons. This result is consistent with literature (25).

When $\mathrm{pH}$ value increased gradually from 2.0 to 12.0 , the oxidation peak current of Sudan 1 at glassy carbon electrode obviously decreased (Fig. 2b). Sudan 1 oxidation peak current was the highest at $\mathrm{pH}=2.0(1.95 \mu \mathrm{A})$, but since this is an extremely acidic medium, phosphate buffer solution at $\mathrm{pH}=5.0$ was used for the determination of Sudan 1. In this medium, Sudan 1 oxidation peak current was $1.90 \mu \mathrm{A}$. As a result, PBS at $\mathrm{pH}=5.0$ was chosen as the supporting electrolyte. a)

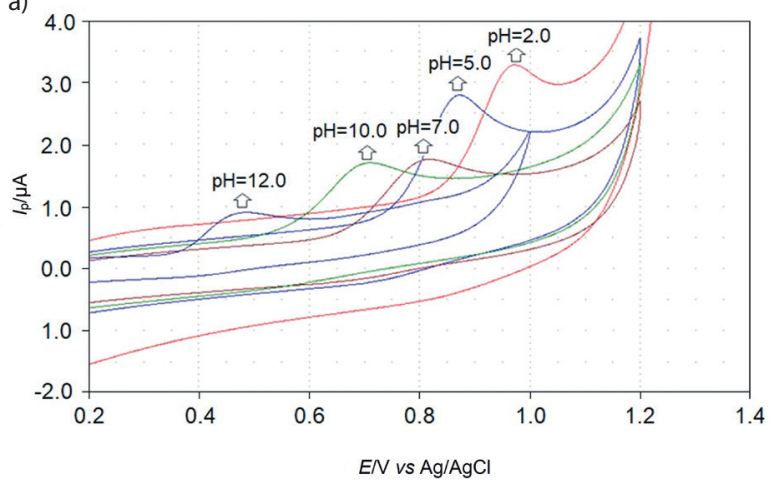

b)

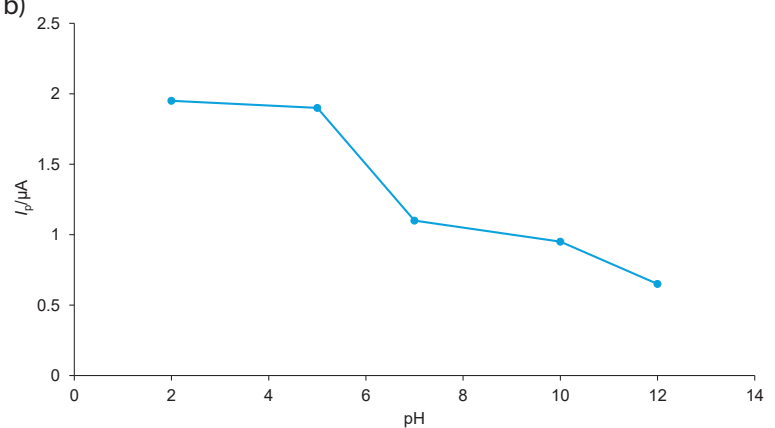

Fig. 2. Cyclic voltammograms of $c($ Sudan 1$)=19.6 \mu M$ recorded on glassy carbon electrode in supporting electrolyte (phosphate-buffered saline (PBS) at $\mathrm{pH}=5.0 \mathrm{in} 75 \%$ methanol): a) at scan rate $100 \mathrm{mV} / \mathrm{s}$ for different $\mathrm{pH}$ values, and $\mathrm{b}$ ) plot of peak currents of Sudan 1 versus $\mathrm{pH}$ value

\section{The effect of the amount of cosolvent}

Sudan dyes are fat-soluble dyes. While Sudan 1 is insoluble in water, it is soluble in various organic solvents (in $\mathrm{mol} / \mathrm{L}$ : trichloromethane 1.49 , dichloromethane 0.57 , toluene 0.30 , benzene 0.17 , acetonitrile 0.04 , ethanol 0.02 and methanol 0.017 ) (26). Solubility of Sudan 1 is similar in methanol and ethanol, so in this study, methanol was chosen as a co-solvent because of its solubility in water and its low toxicity (27). The influence of methanol ratio to Sudan 1-Cu(II) oxidation peak current was studied and changes of peak currents were evaluated in PBS ( $\mathrm{pH}=5.0$ ) supporting electrolyte (Fig. 3).

The highest peak current was obtained in the solution containing $25 \%$ methanol; nevertheless, when the amount of methanol was less than $75 \%$, the Sudan 1 differential pulse

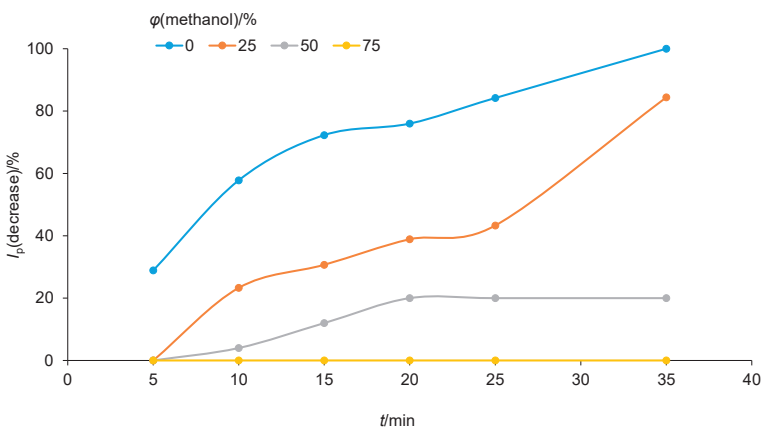

Fig. 3. Influence of methanol volume fractions on stability of Sudan $1-\mathrm{Cu}(\mathrm{II})$ complex with time. $I_{\mathrm{p}}=$ peak current 
voltammogram (DPV) peak current obviously decreased with time. At the end of 35 min, Sudan 1-Cu(II) oxidation peak disappeared in $25 \%$ methanol solution (PBS at $\mathrm{pH}=5.0$ ) and the decrease of peak current was around $85 \%$ in the $50 \%$ methanol solution. Due to the stability of the oxidation peak currents in $75 \%$ methanol aqueous solution, this volume fraction of methanol was chosen for further experiments. For electrochemical studies $5 \mathrm{~mL}$ of supporting electrolyte were used.

\section{Effect of scan rate}

The scan rate is linearly proportional to the peak current according to Randles-Sevcik equation in diffusion-controlled systems:

$$
I_{\mathrm{p}}=k v^{1 / 2}
$$

where $I_{\mathrm{p}}$ is the peak current, and $v$ is the scan rate.

The logarithmic equation between the scan rate and the peak current is given as:

$$
\log I_{\mathrm{p}}=\log k+\mathrm{x} \log v
$$

In diffusion-controlled systems the $x$ value is 0.50 (28). Firstly, the effect of scan rate (from 2.5 to $150 \mathrm{mV} / \mathrm{s}$ ) on oxidation of $c($ Sudan 1$)=2.92 \mu \mathrm{M}$ in supporting electrolyte PBS in $75 \%$ methanol $(\mathrm{pH}=5)$ at the glassy carbon electrode was investigated (Fig. 4a).

From the experimental data, the slope was calculated to be 0.36 (Fig. 4b). This value shows that although this is the adsorption-controlled reaction, there is no significant diffusion effect on it. Then, the effect of scan rate (from 2.5 to $200 \mathrm{mV} / \mathrm{s}$ ) on oxidation of Sudan 1-Cu(II) complex ( $c($ Sudan 1) $=2.92 \mu \mathrm{M}$, $c(\mathrm{Cu}(\mathrm{II}))=17.52 \mu \mathrm{M}$ ) was investigated (Fig. 4c). The slope was calculated to be 0.46 (Fig. 4d). This value shows that although this is a diffusion-controlled reaction, there is no significant adsorption effect on it. The results suggest that the adsorption-controlled electrochemical process changes into diffusion-controlled process with the addition of $\mathrm{Cu}(\mathrm{II})$.

Besides, when the scan rate was studied between 2.5 and $200 \mathrm{mV} / \mathrm{s}$, it was observed that the peak current increased to $125 \mathrm{mV} / \mathrm{s}$, scan rate above $125 \mathrm{mV} / \mathrm{s}$ did not improve the electrochemical current response significantly. Therefore, $125 \mathrm{mV} / \mathrm{s}$ was used as the optimal scan rate for Sudan 1-Cu(II) studies.

\section{Effect of $\mathrm{Cu}(\mathrm{II})$ concentration}

Azo dyes can act as chelating reagents for metal ions. Sudan 1 can react with $\mathrm{Cu}(\mathrm{II})$ to form metal-Sudan complex $(15,16)$, where alkaline solution was preferred for the investigation of interaction between Sudan 1 and copper. In our study, oxidation peak potentials of Sudan 1 at $\mathrm{pH}=5.0$ and 10 (75\% methanol) were 0.879 and $0.489 \mathrm{~V}$, respectively. The oxidation peak potentials of the Sudan 1-Cu(II) complex at $\mathrm{pH}=5.0$ and 10 (75\% methanol) were 0.969 and $0.934 \mathrm{~V}$, respectively. Our study at both $\mathrm{pH}$ values showed that the peak potentials for the oxidation of Sudan 1 and Sudan 1-Cu(II) complex shifted towards negative direction with an increase
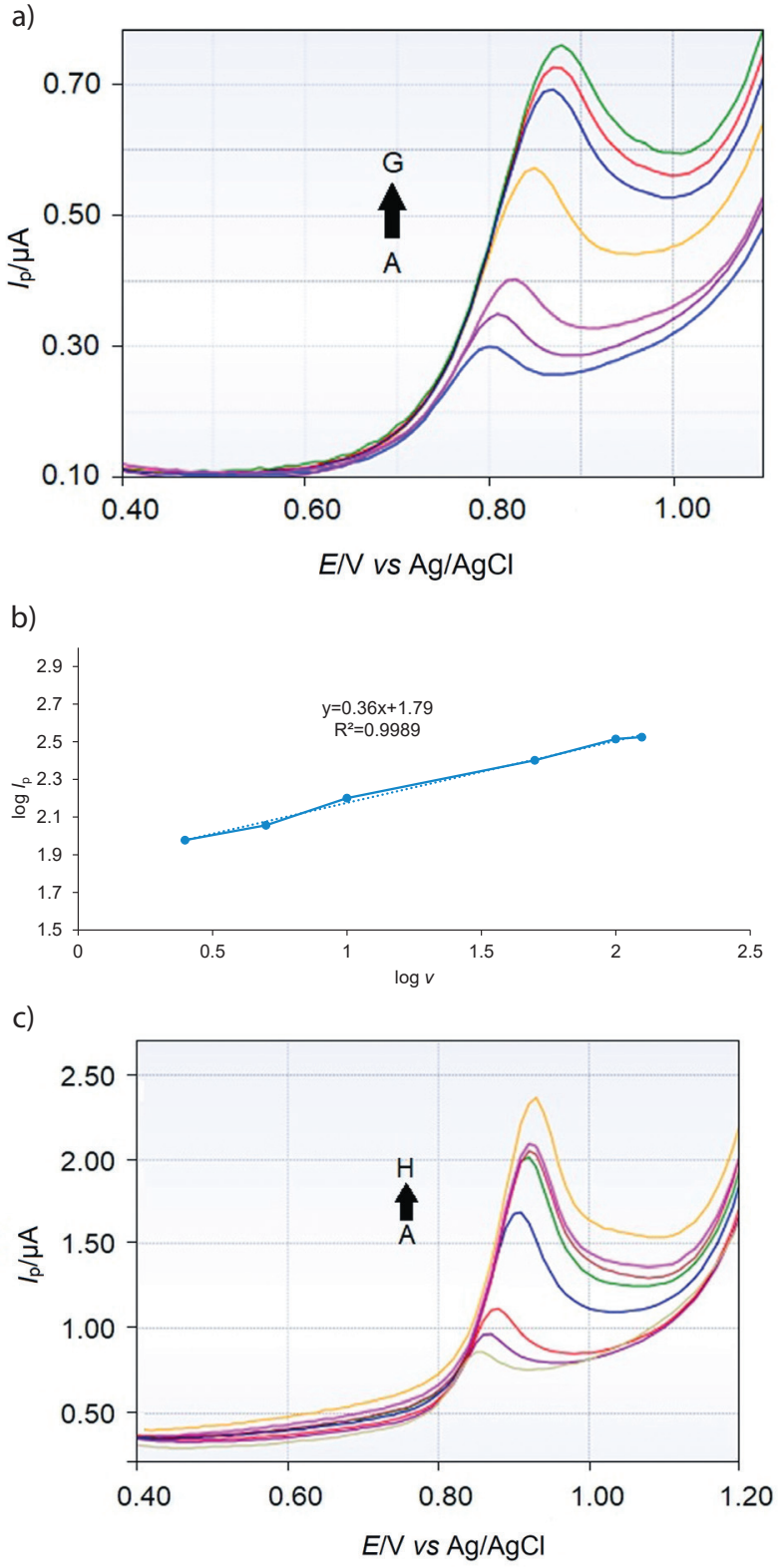

d)

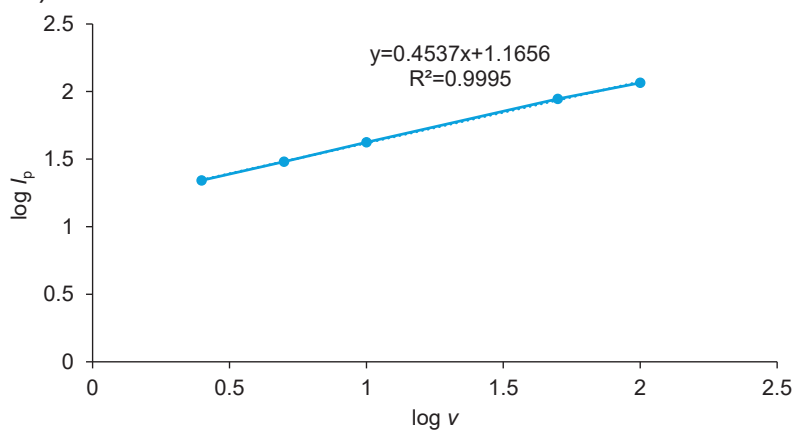

Fig. 4. Differential pulse voltammograms of $c($ Sudan 1$)=2.92 \mu \mathrm{M}$ recorded on glassy carbon electrode in supporting electrolyte phosphate-buffered saline in $75 \%$ methanol $(\mathrm{pH}=5.0)$ : a) different scan rates: $2.5,5.0,10,50,100,125,150 \mathrm{mV} / \mathrm{s}$ (from $A$ to $G$ ), b) influence of scan rate $(v)$ on peak current $\left(I_{\mathrm{p}}\right)$ of Sudan $\left.1, \mathrm{c}\right)$ Sudan 1-Cu(II) complex: $c(\mathrm{Cu}(\mathrm{II}))=17.52 \mu \mathrm{M}$ at different scan rates (from $\mathrm{A}$ to $\mathrm{H})$, and d) influence of scan rate $(v)$ on peak current $\left(I_{\mathrm{p}}\right)$ of Sudan 1-Cu(II) complex 
in the $\mathrm{pH}$ and the oxidation peak currents of Sudan 1-Cu(II) at $\mathrm{pH}=5.0$ and 10 (75\% methanol) were $1.53 \cdot 10^{-6}$ and $0.88 \cdot 10^{-6}$ A. As the peak current at $\mathrm{pH}=5.0$ was twofold higher than at $\mathrm{pH}=10.0$, we used $\mathrm{pH}=5.0$ for the determination of Sudan 1 .

The influence of $\mathrm{Cu}(\mathrm{II})$ concentration on oxidation peak current value of $19.6 \mu \mathrm{M}$ Sudan 1 was investigated in PBS at $\mathrm{pH}=5.0$ (75\% methanol). When $\mathrm{Cu}(\mathrm{II})$ concentration gradually increased from 19.6 to $130.7 \mu \mathrm{M}$, the oxidation peak currents of Sudan 1-Cu(II) increased. The oxidation peak currents and oxidation potential of Sudan 1-Cu(II) increased gradually and reached the maximum value at $120.06 \mu \mathrm{M} \mathrm{Cu}$ (II) (Fig. 5).

a)

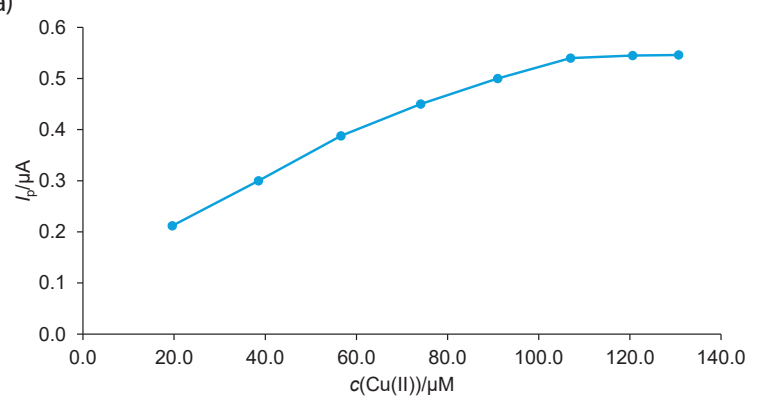

b)

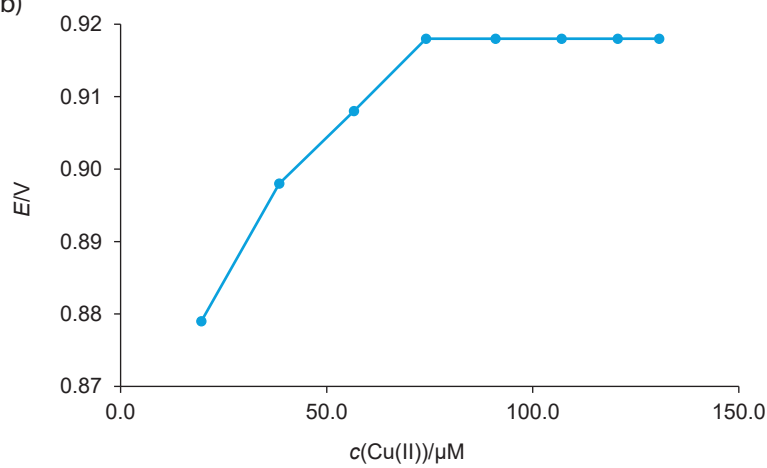

Fig. 5. The influence of $\mathrm{Cu}(\mathrm{II})$ concentration on: a) the oxidation peak current value of $c$ (Sudan 1)=19.6 $\mu \mathrm{M}$, and b) the shift of Sudan 1-Cu(II) complex oxidation potential

Therefore, 6-fold concentration of Cu(II) was used for the determination of Sudan 1 in synthetic and real samples.

\section{Calibration curves for the determination of Sudan 1}

DPV had a higher sensitivity than CV for analytical determination of Sudan 1 (29). Fig. 6a shows the differential pulse voltammograms of Sudan 1-Cu(II) complex recorded under optimized conditions. The DPV oxidation peak current of Sudan $1-\mathrm{Cu}$ (II) complex increased with the increasing concentration of Sudan 1. In the concentration range from 0.04 to $5.32 \mu \mathrm{M}$, two linear ranges can be seen in the insert of Fig. $6 \mathrm{~b}$. These ranges can be obtained in a range between 0.04-0.09 and 0.09-5.3 $\mu \mathrm{M}$. The corresponding regression equations can be expressed as:

$$
I_{\mathrm{pa}}=1.441 \mathrm{c}+0.0085\left(\mathrm{R}^{2}=0.9972\right)
$$

and

$$
I_{p a}=0.227 c+0.0969\left(R^{2}=0.9979\right)
$$

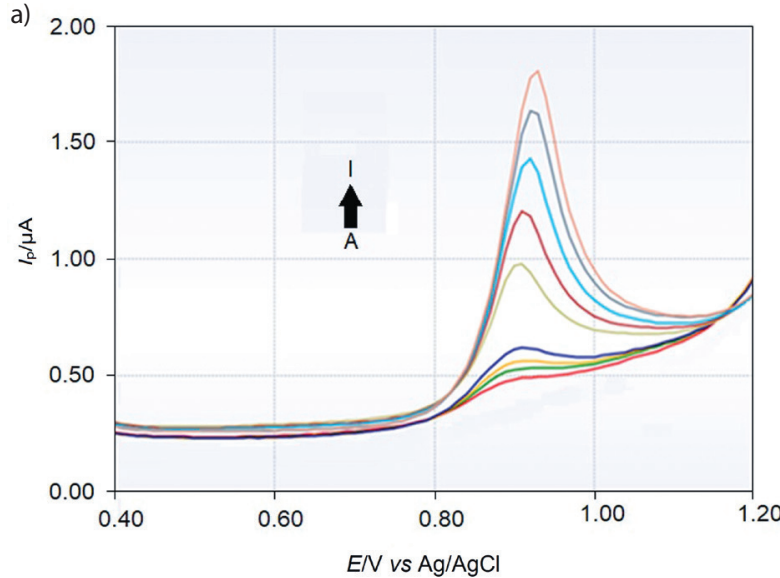

b)

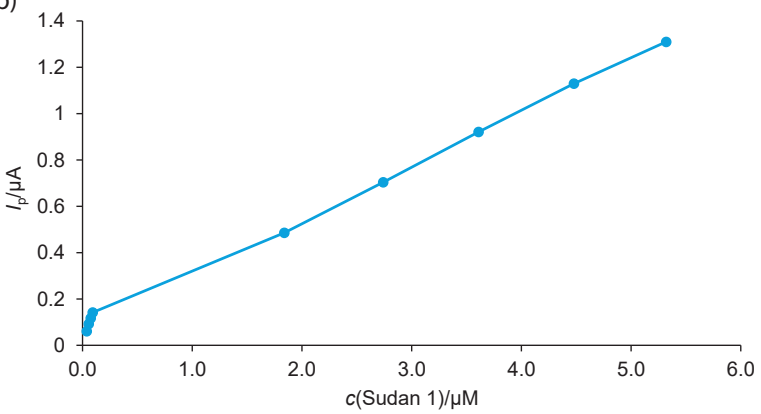

Fig. 6. Differential pulse voltammograms of Sudan 1-Cu(II) complex in phosphate buffered saline $(\mathrm{pH}=5.0,70 \%$ methanol) as supporting electrolyte: a) $c(\mathrm{Cu}(\mathrm{II}))=31.32 \mu \mathrm{M}, c($ Sudan 1) (from a to i): $0.04,0.06$, $0.08,0.09,1.8,2.7,3.6,4.5$ and $5.3 \mu \mathrm{M}$, and b) linear relationship between the peak currents and the Sudan 1 concentration. Scan rate: $125 \mathrm{mV} / \mathrm{s}$

Two slopes were observed with two different regions. This is because higher concentrations of Sudan 1 molecules are attached at the interface, and thus, the saturation occurs in the system, resulting in lower signal in the current value (30). The limit of detection (LOD) was estimated to be $0.71 \mathrm{nM}(\mathrm{S} / \mathrm{N}=3)$.

For the evaluation of the prevalence of this work, Table 1 $(19,20,25,31-33)$ compares our results with the literature findings, and shows that the detection limit of Sudan 1 is lower than those of previously reported works.

Firstly, the quantitative analysis of Sudan 1 was carried out by the DPV under the optimum conditions such as PBS at $\mathrm{pH}=5.0$ (75\% methanol), scan rate $125 \mathrm{mV} / \mathrm{s}$, and 6-fold concentration of $\mathrm{Cu}(\mathrm{II})$. The analysis of the known concentrations of samples was repeated five times using the glassy carbon electrode. The data in Table 2 show that the quantitative determination of Sudan 1 involves a very small error and standard deviation.

In real samples, standard addition method was carried out and each sample was determined five times under the optimized conditions (Table 2). For comparison, the Sudan 1 concentrations in food samples were also determined by HPLC (34). The electrochemical results show good agreement with HPLC results. The percentage recoveries ranged from 97.71 to 102.21, which indicates that the developed method may have useful applications in food samples. 
Table 1. The comparison of the determination of Sudan 1 in this study with previously reported ones

\begin{tabular}{lccc} 
Electrode & Method & LOD/nM & \multicolumn{1}{c}{ Linear range/M } \\
$\begin{array}{l}\text { Ag nanoparticles on graphene oxide- } \\
\text { modified glassy carbon }\end{array}$ & Amperometry & 1140.0 & $(3.90-31.90) \cdot 10^{-5}$ \\
Multi-wall carbon nanotube & SWV & 20.10 & $4.03 \cdot 10^{-8}-4.03 \cdot 10^{-6}$ \\
Graphene-modified glassy carbon & CV & 40.0 & $7.50 \cdot 10^{-8}-7.50 \cdot 10^{-6}$ \\
Expanded graphite paste & DPV & 0.90 & $5.0 \cdot 10^{-9}-7.0 \cdot 10^{-6}$ \\
Platinum nanoparticles attached to & DPV & 1.60 & $(20)$ \\
graphene- $\beta$-cyclodextrin & SW-ASV & 1.20 & $(31)$ \\
Graphene-ZnSe quantum dots hybrid & DPV & 0.71 & $(0.38-0.93) \cdot 10^{-9}-68.68 \cdot 10^{-6}$ \\
Non-modified glassy carbon & & $(0.93-53.2) \cdot 10^{-7}$ & This work
\end{tabular}

LOD=limit of detection

Table 2. The determination of Sudan 1 in synthetic and food samples

\begin{tabular}{|c|c|c|c|c|c|c|}
\hline Sample & $c(\text { Sudan } 1)_{\text {added }} / 10^{-7} \mathrm{M}$ & $c(\text { Sudan } 1)_{\text {found }}^{*} / 10^{-7} \mathrm{M}$ & Recovery/\% & $\mathrm{RSD} / \%$ & $\begin{array}{l}\text { Reliability range }{ }^{* *} \\
c(\text { Sudan } 1) / 10^{-7} \mathrm{M}\end{array}$ & $\begin{array}{c}\text { Determination } \\
\text { by HPLC } \\
\text { c(Sudan } 1) / 10^{-7} \mathrm{M}\end{array}$ \\
\hline Synthetic sample 1 & 0.66 & $0.66 \pm 0.03$ & 100.51 & 4.17 & $0.66 \pm 0.03$ & $0.66 \pm 0.03$ \\
\hline Synthetic sample 2 & 2.38 & $2.37 \pm 0.02$ & 99.87 & 0.80 & $2.37 \pm 0.02$ & $2.38 \pm 0.02$ \\
\hline Chilli sauce & $\begin{array}{l}2.76 \\
4.42\end{array}$ & $\begin{array}{l}2.73 \pm 0.02 \\
4.46 \pm 0.01\end{array}$ & $\begin{array}{l}98.76 \\
98.60\end{array}$ & $\begin{array}{l}0.62 \\
0.27\end{array}$ & $\begin{array}{l}2.73 \pm 0.02 \\
4.46 \pm 0.02\end{array}$ & $\begin{array}{l}2.75 \pm 0.02 \\
4.46 \pm 0.02\end{array}$ \\
\hline Tomato sauce & $\begin{array}{l}2.76 \\
4.42\end{array}$ & $\begin{array}{l}2.78 \pm 0.02 \\
4.48 \pm 0.03\end{array}$ & $\begin{array}{l}100.60 \\
99.19\end{array}$ & $\begin{array}{l}0.68 \\
0.58\end{array}$ & $\begin{array}{l}2.78 \pm 0.02 \\
4.48 \pm 0.03\end{array}$ & $\begin{array}{l}2.77 \pm 0.01 \\
4.50 \pm 0.03\end{array}$ \\
\hline Chilli power & $\begin{array}{l}2.76 \\
4.42\end{array}$ & $\begin{array}{l}2.71 \pm 0.01 \\
4.44 \pm 0.02\end{array}$ & $\begin{array}{l}98.19 \\
98.23\end{array}$ & $\begin{array}{l}0.52 \\
0.49\end{array}$ & $\begin{array}{l}2.71 \pm 0.02 \\
4.44 \pm 0.03\end{array}$ & $\begin{array}{l}2.72 \pm 0.01 \\
4.48 \pm 0.02\end{array}$ \\
\hline Ketchup & $\begin{array}{l}2.76 \\
4.42\end{array}$ & $\begin{array}{l}2.70 \pm 0.02 \\
4.62 \pm 0.02\end{array}$ & $\begin{array}{c}97.71 \\
102.21\end{array}$ & $\begin{array}{l}0.63 \\
0.48\end{array}$ & $\begin{array}{l}2.70 \pm 0.02 \\
4.62 \pm 0.03\end{array}$ & $\begin{array}{l}2.75 \pm 0.01 \\
4.46 \pm 0.02\end{array}$ \\
\hline
\end{tabular}

${ }^{*}$ Result $=\mathrm{x}^{-} \pm \mathrm{sx} ;{ }^{* * 95} \%$ reliability level, $N=5 ; \mathrm{RSD}=$ relative standard deviation

\section{Interference studies}

The influence of some potential interfering species, such as Sudan 2-4, glucose, fructose and sucrose, on the determination of $2.82 \mu \mathrm{M}$ Sudan 1 was studied by DPV. The results indicate that 25 times higher concentrations of glucose, fructose and sucrose would not affect the determination of Sudan 1. There was a $5 \%$ decrease in peak current because of increasing supporting electrolyte volume; nevertheless, there was no deformation in the shape of the peak or any shift in Sudan 1 oxidation potential. Under the same conditions, the effects of Sudan 2-4 were investigated and it was detected that 0.04 times higher concentration of Sudan 2, and 0.03 times higher concentrations of Sudan 3 and Sudan 4 had an influence on the signal of Sudan 1. There was a deformation in the shape of the peak and shift in Sudan 1 oxidation potential. The total approximate content of all Sudan compounds such as Sudan 1-4 might be detected using this method in food samples.

Metal ions $\mathrm{Ca}^{2+}, \mathrm{Mg}^{2+}, \mathrm{Al}^{3+}, \mathrm{Na}^{+}, \mathrm{Fe}^{3+}$ and $\mathrm{Zn}^{2+}$ can be found in food samples. Previous studies show that about 1000 -fold concentration of these metal ions has almost no influence on the electrochemical determination of Sudan $1(35,36)$, so the interference effects of these metals were not investigated in this study.

\section{CONCLUSIONS}

We developed a simple, sensitive, inexpensive and selective electrochemical method for the determination of Sudan 1 in foods by differential pulse voltammetry based on the addition of methanol and $\mathrm{Cu}(\mathrm{II})$. The electrochemical response of Sudan 1 remarkably increased in the presence $\mathrm{Cu}(\mathrm{III})$. In all previous studies, Sudan 1 was determined by a modified electrode; however, this method needs no modification and the detection limit was much lower $(0.71 \mathrm{nM})$ than previously reported values. The interference effects of Sudan 2-4 were demonstrated in this study.

\section{CONFLICT OF INTEREST}

We declare that we have no conflict of interest.

\section{ACKNOWLEDGEMENT}

This study was supported by Gazi University, Projects of Scientific Investigation (No: 05/2016-06) and Life Sciences Application and Research Center, Gazi University, Ankara, Turkey.

\section{REFERENCES}

1. Leo L, Loong C, Ho XL, Raman MFB, Tian Suan MY, Loke WM. Occurrence of azo food dyes and their effects on cellular inflammatory responses. Nutrition. 2018;46:36-40.

https://doi.org/10.1016/j.nut.2017.08.010

2. Lipskikh OI, Korotkova El, Khristunova YP, Barek J, Kratochvil B. Sensors for voltammetric determination of food azo dyes - A critical review. Electrochim Acta. 2018;260:974-85. https://doi.org/10.1016/j.electacta.2017.12.027 
3. Reddy C, Kumar AN, Mohan SV. Metabolic phasing of anoxic-PDBR for high rate treatment of azo dye wastewater. J Hazard Mater. 2018;343:49-58.

https://doi.org/10.1016/j.jhazmat.2017.08.065

4. Sun $\mathrm{H}$, Xia Q, Liu R. Comparison of the binding of the dyes Sudan II and Sudan IV to bovine hemoglobin. J Lumin. 2014; 48:143-50.

https://doi.org/10.1016/j.jlumin.2013.12.012

5. Petrakis E, Cagliani LR, Tarantillis PA, Polissiou MG, Consonni R. Sudan dyes in adulterated saffron (Crocus sativus L): Identification and quantification by ${ }^{1} \mathrm{H}$ NMR. Food Chem. 2017;217:418-24.

https://doi.org/10.1016/j.foodchem.2016.08.078

6. Wang M, Chen Z, Chen Y, Zhan C, Zhao J. New synthesis of self-assembly ionic liquid functionalized reduced graphene oxide-gold nanoparticle composites for electrochemical determination of Sudan I. J Electroanal Chem. 2015;756:49-55. https://doi.org/10.1016/j.jelechem.2015.08.007

7. Kong X, Squire K, Chong X, Wang AX. Ultra-sensitive lab-on-achip detection of Sudan I in food using plasmonics-enhanced diatomaceous thin film. Food Control. 2017;79:258-65.

https://doi.org/10.1016/j.foodcont.2017.04.007

8. Piatkowska M, Jedziniak P, Olejnik M, Żmudzki J, Posyniak A. Absence of evidence or evidence of absence? A transfer and depletion study of Sudan I in eggs. Food Chem. 2018; 239:598-602.

https://doi.org/10.1016/j.foodchem.2017.06.156

9. Benmassaoud Y, Villaseñor AJ, Salghi R, Jodeh S, Algarra M, Zougagh M, Ríos A. Magnetic/non-magnetic argan press cake nanocellulose for the selective extraction of sudan dyes in food samples prior to the determination by capillary liquid chromatograpy. Talanta. 2017;166:63-9.

https://doi.org/10.1016/j.talanta.2017.01.041

10. López MI, Ruisánchez I, Callao MP. Figures of merit of a SERS method for Sudan I determination at traces levels. Spectrochim Acta A. 2013;111:237-41.

https://doi.org/10.1016/j.saa.2013.04.031

11. Zhu H, Chen Y, Huang C, Han Y, Zhang Y, Xie S, Chen X, Jin M. Simultaneous determination offour Sudan dyes in rat blood by UFLC-MS/MS and its application to a pharmacokinetic study in rats. J Pharm Anal. 2015;5(4):239-48.

https://doi.org/10.1016/j.jpha.2015.03.001

12. Enríquez-Gabeiras L, Gallego A, Garcinuño RM, Fernández-Hernando P, Durand JS. Interference-free determination of illegal dyes in sauces and condiments by matrix solid phase dispersion (MSPD) and liquid chromatography (HPLC-DAD). Food Chem. 2012;135(1):193-8.

https://doi.org/10.1016/j.foodchem.2012.04.065

13. Yu W, Liu Z, Li Q, Zhang H, Yu Y. Determination of Sudan IIV in candy using ionic liquid/anionic surfactant aqueous two-phase extraction coupled with high-performance liquid chromatography. Food Chem. 2015;173:815-20.

https://doi.org/10.1016/j.foodchem.2014.10.091
14. Sricharoen $P$, Limchoowong N, Techawongstien S, Chanthai S. Ultrasound-assisted emulsification microextraction coupled with salt-induced demulsification based on solidified floating organic drop prior to HPLC determination of Sudan dyes in chili products. Arab JChem. 2017; in press.

https://doi.org/10.1016/j.arabjc.2016.12.020

15. Huang ST, Yang LF, Li NB, Luo HQ. An ultrasensitive and selective fluorescence assay for Sudan I and III against the influence of Sudan II and IV. Biosens Bioelectron. 2013;42:136-40. https://doi.org/10.1016/j.bios.2012.10.093

16. Huo J, Guo Y, Meng S, Wang M, Wang Y. Complex formation of Sudan I with $\mathrm{Cu}(\mathrm{II})$ and its identification from chilli species. Proceedings of the 4th International Conference on Bioinformatics and Biomedical Engineering; 2010 June 18-22, Chengdu, PR China: IEEE, Piscataway, NJ, USA; 2010. https://doi.org/10.1109/ICBBE.2010.5515322

17. Li BL, Luo JH, Luo HQ, Li NB. A novel conducting poly(p-aminobenzene sulphonic acid)-based electrochemical sensor for sensitive determination of Sudan I and its application for detection in food stuffs. Food Chem. 2015;173:594-9. https://doi.org/10.1016/j.foodchem.2014.10.060

18. Yang D, Zhu L, Jiang $X$, Guo L. Sensitive determination of Sudan I at an ordered mesoporous carbon modified glassy carbon electrode. Sens Actuators B Chem. 2009;141(1):124-9. https://doi.org/10.1016/j.snb.2009.05.030

19. Prabakaran E, Pandian K. Amperometric detection of Sudan I in red chili powder samples using Ag nanoparticles decorated graphene oxide modified glassy carbon electrode. Food Chem. 2015;166:198-205.

https://doi.org/10.1016/j.foodchem.2014.05.143

20. Gan T, Li K, Wu K. Multi-wall carbon nanotube-based electrochemical sensor for sensitive determination of Sudan I. Sens Actuators B Chem. 2008;132(1):134-9. https://doi.org/10.1016/j.snb.2008.01.013

21. Yang $D$, Zhu $L$, Jiang $X$. Electrochemical reaction mechanism and determination of Sudan I at a multi wall carbon nanotubes modified glassy carbon electrode. J Electroanal Chem. 2010;640(1-2):17-22.

https://doi.org/10.1016/j.jelechem.2009.12.022

22. Rauf MA, Akhter Z, Kanwal S. Photometric studies of the complex formation of $\mathrm{Cu} 2+$ and $\mathrm{Cr} 3+$ ions with Sudan Red B. Dyes Pigm. 2005;67(1):77-9.

https://doi.org/10.1016/j.dyepig.2004.10.009

23. Esme A, Sagdinc SG, Yildiz SZ. Experimental and theoretical studies on Sudan Red G [1-(2-methoxyphenylazo)-2-naphthol] and its $\mathrm{Cu}(\mathrm{II})$ coordination compound. J Mol Struct. 2014;1075:264-78.

https://doi.org/10.1016/j.molstruc.2014.07.009

24. Orojloo M, Zolgharnein P, Solimannejad M, Amani S. Synthesis and characterization of cobalt (II), nickel (II), copper (II) and zinc (II) complexes derived from two Schiff base ligands: Spectroscopic thermal magnetic moment 
electrochemical and antimicrobial studies. Inorg Chim Acta. 2017; 467:227-37.

https://doi.org/10.1016/j.ica.2017.08.016

25. Ma X, Chao M, Wang Z. Electrochemical determination of Sudan I in food samples at graphene modified glassy carbon electrode based on the enhancement effect of sodium dodecyl sulphonate. Food Chem. 2013;138(2-3):739-44. https://doi.org/10.1016/j.foodchem.2012.11.004

26. Rebane R, Leito I, Yurchenko S, Herodes K. A review of anaIytical techniques for determination of Sudan I-IV dyes in food matrixes. J Chromatogr A. 2010;1217(17):2747-57. https://doi.org/10.1016/j.chroma.2010.02.038

27. Jiao J, Wang J, Li M, Li J, Li Q, Quan Q, Chen J. Simultaneous determination of three azo dyes in food product by ion mobility spectrometry. J Chromatogr B. 2016;1025:105-9. https://doi.org/10.1016/j.jchromb.2016.05.002

28. Karaboduk K, Hasdemir E, Aksu ML. Palladium coated steel electrode - Preparation characterization and their use of borohydride determination. GU J Sci. 2015;28(3):377-85.

29. Yin H, Zhou Y, Meng X, Tang T, Ai S, Zhu L. Electrochemical behaviour of Sudan I at $\mathrm{Fe}_{3} \mathrm{O}_{4}$ nanoparticles modified glassy carbon electrode and its determination in food samples. Food Chem. 2011;127(3):1348-53.

https://doi.org/10.1016/j.foodchem.2011.01.097

30. Bhattacharya G, Mathur A, Pal S, McLaughlin J, Roy SS. Equivalent circuit models and analysis of electrochemical impedance spectra of caffeine solutions and beverages. Int J Electrochem Sci. 2016;11:6370-86. https://doi.org/10.20964/2016.07.86
31. Zhang J, Wang M, Shentu C, Wang W, He Y, Chen Z. Electrochemical detection of Sudan I by using an expanded graphite paste electrode. J Electroanal Chem. 2012;685:47-52. https://doi.org/10.1016/j.jelechem.2012.08.041

32. Palanisamy S, Kokulnathan T, Chen SM, Velusamy V, Ramaraj SK. Voltammetric determination of Sudan I in food samples based on platinum nanoparticles decorated on graphene- $\beta$-cyclodextrin modified electrode. J Electroanal Chem. 2017;794:64-70.

https://doi.org/10.1016/j.jelechem.2017.03.041

33. Wang L, Yang R, Li J, Qu L, Harrington PB. High-sensitive electrochemical sensor of Sudan I based ontemplate-directed self-assembly of graphene-ZnSe quantum dots hybrid structure. Sens Actuators B Chem. 2015;215:181-7.

https://doi.org/10.1016/j.snb.2015.03.034

34. Ertaş $\mathrm{E}$, Özer $\mathrm{H}$, Alasalvar C. A rapid HPLC method for determination of Sudan dyes and Para Red in red chilli pepper. Food Chem. 2007;105(2):756-60.

https://doi.org/10.1016/j.foodchem.2007.01.010

35. Gan T, Li K, Wu K. Multi-wall carbon nanotube-based electrochemical sensor for sensitive determination of Sudan I. Sens Actuators B Chem. 2008;132(1):134-9.

https://doi.org/10.1016/j.snb.2008.01.013

36. Elyasi M, Khalilzadeh MA, Karimi-Maleh H.High sensitive voltammetric sensor based on Pt/CNTs nanocomposite modified ionic liquid carbon paste electrode for determination of Sudan I in food samples. Food Chem. 2013;141(4):4311-7.

https://doi.org/10.1016/j.foodchem.2013.07.020 